\title{
Pedagogias da alteridade. Perspectivas sobre a emoção de lidar: Manuela Malpique e Nise da Silveira
}

\author{
Pedagogies of otherness. Perspectives on the emoção de lidar: \\ Manuela Malpique and Nise da Silveira
}

\author{
Vera Coimbra CERQUEIRA ${ }^{1}$ \\ Margarida Louro FELGUEIRAS²
}

\begin{abstract}
Resumo
Pretende-se apresentar a obra de duas personalidades singulares nas suas áreas de atuação, cujos interesses um dia se cruzaram, dado os seus trabalhos confluírem na relevância atribuída ao estabelecimento da harmonia entre os estados físico, mental, emocional e espiritual. Manuela Malpique desenvolveu atividades pedagógicas e psicoterapêuticas no campo da imaginativa onírica. Nise da Silveira, psiquiatra, pioneira no uso da terapia ocupacional no contexto hospitalar, abriu caminho para a expressão plástica de doentes mentais marginalizados pela sociedade, pela ciência. $\mathrm{O}$ estudo histórico e teórico, com recurso a entrevistas, evidencia a relaçáo entre educação, terapia e arte teorizado e praticado pelas biografadas.
\end{abstract}

Palavras-chave: Educação. Terapia. Arte. Pedagogia da Alteridade.

\begin{abstract}
We intend to present the work of two singular personalities in their areas of activity, whose interests once crossed, since their work converge on the relevance attributed to the establishment of harmony between physical, mental, emotional and spiritual states. Manuela Malpique developed pedagogical and psychotherapeutic activities in the field of oneiric imagination. Nise da Silveira, a psychiatrist, pioneer in the use of occupational therapy in the hospital context, paved the way for the plastic expression of mental patients marginalized by society and science. Through a historical and theoretical study, using interviews, we propose to highlight the relationship between education, therapy and art.
\end{abstract}

Keywords: Education. Therapy. Art. Pedagogies of Otherness.

1 Mestre em Educação, GT História da Educação, Herança Cultural e Museologia da FPCEUP, E-mail: <veracoimbracerqueira@gmail.com>.

2 Professora Associada da FPCE-UP. Coordenadora do GT História da Educação, Herança Cultural e Museologia da FPCE-UP e membro do CIIE. Faculdade de Psicologia e de Ciências da Educação da Universidade do Porto. Rua Alfredo Allen, 4200-135, Porto, Portugal. Tel.: +351 226079700 -Email: $<$ margafel@fpce.up.pt> e <margalf@gmail.com>.

\begin{tabular}{l|l|l|l|l|l} 
R. Educ. Públ. & Cuiabá & v. 27 & n. 66 & p. $927-949$ & set./dez. 2018 \\
\hline
\end{tabular}




\section{Introdução}

Este artigo pretende chamar ao debate educativo, em contexto formal em cuidados e prevenção em termos da saúde mental, as pedagogias da alteridade, que valorizam as atividades expressivas e o convívio afetivo entre os vários agentes. Para tal, são convocadas à nossa memória duas personalidades, uma brasileira e outra portuguesa, cujas vidas se cruzaram: Manuela Malpique e Nise da Silveira.

Privilegiamos uma abordagem histórica com o intuito de refletir sobre as práticas inovadoras dessas autoras no campo da educaçáo e da terapia ocupacional. Definimos como objetivos: dar a conhecer duas personalidades cujo trabalho se apresenta como inovador; conhecer a fundamentação teórica das práticas desenvolvidas nos espaços orientados e/ou por elas criados; aferir o relevo atribuído à emoção e ao Ser nos contextos de formação e de terapia.

\section{Manuela Malpique: a mulher e profissional de excelência}

Dividida, na minha formação, pelas ciências exactas, mas simultaneamente pelas ciências humanas, inerentes à arquitectura e exigidas pelas ciências da educação, fui desenvolvendo em mim, sem o saber, mas tomando disso consciência agora, estas duas vertentes, na aparência opostas - o racional e o irracional. (MALPIQUE, 2002, p. 131).

Por meio do seu espólio e da consulta de outras publicaçôes tivemos acesso a uma experiência de vida passada, cuja análise teve como premissa "dar sentido, não tanto ao passado, como ao próprio presente.” (GUARINELLO, 1993, p. 187188). Ciente de que "como pedagoga, Manuela não apresentou um texto que tivesse pretensão de ser olhado como uma teoria ou a sua pedagogia, devidamente explanada" (FELGUEIRAS, 2007, p. 24), pretendemos delinear o percurso das suas opçóes pedagógicas de alteridade.

Em $14^{3}$ de agosto de 1932, em Faro, nasceu aquela que viria a ser uma mulher multifacetada - arquiteta, pedagoga, investigadora, professora, psicoterapeuta, técnica de expressão plástica, Manuela Brasil Soares Malpique. Dividida entre a pedagogia e a terapia, marcou quem com ela teve oportunidade de conviver, trabalhar e aprender.

3 É um dado curioso, embora no seu livro, História de Vida, mencione que nasceu a 7 de agosto de 1932. Ao preencher, por exemplo, formulários de candidatura a projetos individuais, indica o dia 14. 
O seu passaporte repleto de viagens reais e imaginárias teve o seu primeiro carimbo quando, ainda criança, foi para Angola, onde o pai fora colocado como professor de liceu (FELGUEIRAS, 2007). Já adolescente, regressou ao Porto, onde fez o Curso Especial de Arquitetura na Escola Superior de Belas Artes do Porto (ESBAP) (1951-1955).

No período de 1982 a 1984 foi destacada para a Divisão do Ensino Especial como Coordenadora Regional da Deficiência Mental da Zona Norte. No período de 1984 a 1988 foi bolseira da Fundaçáo Calouste Gulbenkian, Serviço de Belas Artes, o que lhe possibilitou deslocaçóes, no âmbito da investigação, a Paris, Bordéus e Göttingen, bem como a concretização da sua tese de doutoramento. Foi em 1987 que obteve o diploma de oniroterapeuta ${ }^{4}$ pela Société Internationale des Techniques de L'Imagerie Mentale Onirique (SITIMO), fundada em Paris, por André Virel, em 1968, e de que se tornou vice-presidente do Secretariado da SITIMO em Portugal ${ }^{5}$, sucedendo ao Dr. Azevedo Fernandes.

Em 1988, aceita o convite de Bártolo da Paiva Campos para integrar, como professora assistente, o núcleo inicial da Licenciatura de Ciências da Educação da Faculdade de Psicologia e de Ciências da Educação da Universidade do Porto, onde veio a lecionar a disciplina anual Desenvolvimento Socioemocional e Técnicas de Expressão e aulas práticas de Educação de Crianças como Necessidades Educativas Especificas. Concluiu, em 1995, o Doutoramento em Ciências da Educação, na especialidade Educação da Criança, com a apresentação da tese Pequenas Histórias: a Geografia das Crianças. Práticas e representaçóes de lugares do dia-a-dia de crianças portuguesas em idade escolar.

Como investigadora do Centro de Investigação e Intervenção Educativa (CIIE) ${ }^{6}$, iniciou, em 1989, o Projeto de Imaginativa Onírica. Traços para uma Biografia Escondida, com uma equipe composta por Isabel Lima e Ana Azevedo. Tinha como objetivos o tratamento da informação por ela recolhida de 1989 a 1996, a caracterização da população e das imagens com vista à sua inclusão numa Biblioteca Digital de Imagens do Inconsciente, devidamente autorizados pelos/as autores/as.

Embora já acossada pela doença que a vitimou, em 1998, realizou a terceira viagem ao Brasil, que a levou ao Rio de Janeiro para o conhecer e reunir

\footnotetext{
4 Anteriormente, em 1973, já havia feito formação em técnicas de imaginativa onírica com André Virel.

5 Secretariado da SITIMO era no Hospital Magalhães Lemos, no Porto.

6 Unidade de investigação financiada pela Fundação Ciência e Tecnologia (FCT) e que tem como instituição de acolhimento a Faculdade de Psicologia e de Ciências da Educaçáo da Universidade do Porto. No CIIE integrou a Linha 3 - Cultura(s), Comunicação e Imaginário.
} 
com a equipe do Museu de Imagens do Inconsciente, no âmbito do Projeto Laboratório de Configuraçóes Espaciais. Essa viagem propiciou o encontro das duas personalidades que inspiram esse trabalho. Na conversa com Nise da Silveira, Manuela reconhece-lhe a importância da sua intervenção na psiquiatria. Manuela Malpique viria a falecer no seu regresso a Portugal, em 22 de janeiro de 1999, no Hospital de São João, no Porto. Muitos projetos e sonhos ficaram por concretizar. A história deixou de ser vivida, para passar a ser contada e relembrada.

De acordo com o testemunho sentido da sua amiga e discípula, Manuela Malpique:

[...] caracterizava-se por valorizar dimensóes que a formação ainda não valorizava. Nesse sentido a Manuela foi extremamente inovadora. Era uma mulher à frente da sociedade do seu tempo. A Manuela era uma mulher extremamente rigorosa, extremamente estruturada. Penso que a sua formação em arquitetura, as suas características personalísticas enquanto arquiteta e investigadora estão bem presentes em tudo o que fez. Por outro lado, está-lhe associada uma forte dimensão estética que se fazia sentir pela valorizaçáo da sensibilidade e pelo modo como enfatizava a comunicação e a expressáo [...]. Por outro lado, era uma mulher extremamente atenta e criativa [...]. (Entrevista a Isabel M.- n. $\left.{ }^{\circ} 1\right)$.

\section{Nise da Silveira: a dignificação dos inumeráveis estados do ser ${ }^{7}$}

Nise $^{8}$ Magalhães da Silveira foi a mulher que lutou contra a exclusão dos doentes mentais, incentivou a sua livre expressáo contra a violência dos tratamentos psiquiátricos e reconheceu aos animais um lugar de coterapeutas no tratamento psiquiátrico.

A sua história começou em Maceió, em Alagoas, onde nasceu em 15 de fevereiro de 1905. Filha única de um casal amante das artes, frequentou o Colégio do Santíssimo Sacramento, de freiras de origem francesa. O pai teve grande

7 "O ser tem estados inumeráveis e cada vez mais perigosos." (Antonin Artaud. In: Cahiers d'Art, 1951). Nise (1986) acredita que através da sua própria experiência Artaud conseguiu, melhor do que ninguém, exprimir, por meio da palavra, as suas vivências internas.

8 Nome escolhido pelos seus pais a partir dos sonetos de Cláudio Manuel da Costa, um dos idealizadores do Movimento de Insurreição Mineira, que pretendia libertar o Brasil do colonialismo (MELO, 2007). 
influência nos seus gostos literários, dando-lhe a conhecer obras de Machado de Assis e Spinoza.

Aos 15 anos $^{9}$ entrou na Faculdade de Medicina da Bahia. Era a única mulher da turma e da faculdade, onde estudavam 157 rapazes. Concluiu o curso em 28 de dezembro de $1926 \mathrm{com}$ a tese inaugural Ensaio sobre a Criminalidade das Mulheres na Bahia, de cunho eminentemente higienista (MELO, 2006). Nela estudou os casos de assassinas, ladras e prostitutas no presídio de Salvador, revelando a sua preocupação com a condição social e a segregação da mulher.

A morte do pai, aos 47 anos e um mês depois de Nise se formar, em fevereiro de 1927, é o acontecimento que marca a sua mudança para o Rio de Janeiro (CALIXTO, 2017). Em 1933, assumiu o cargo de psiquiatra no Hospital Psiquiátrico da Praia Vermelha, como assistente e aluna do catedrático de neurologia António

Austregésilo, que a inscreveu, sem o seu consentimento, no concurso.

É nesse hospital, onde passa a residir, que é presa pela segunda vez ${ }^{10}$, por denúncia de uma enfermeira, que viu sobre a mesa de Nise obras de Marx e a denunciou à administração do hospital. Saiu da prisão no dia 21 de junho de 1937.

Com a onda de redemocratização do país (POMPEU; SILVA; REILY, 2012) e com a ajuda do então diretor da Saúde Pública, Barros Barreto, regressou em 1944 à sua atividade profissional no Centro Psiquiátrico Nacional de Pedro II, no Engenho de Dentro, hoje Instituto Municipal de Assistência à Saúde Nise da Silveira. Nesse Centro, confrontou-se com os tratamentos e medicamentos em voga, o eletrochoque e a lobotomia. Sempre renunciou ao uso desses novos tratamentos e começou a focar a sua atençáo no tratamento dos doentes por meio da terapia ocupacional.

Com a verba de 30 contos de réis, destinada ao sector de terapia ocupacional, e a relevante ajuda de Almir Mavignier iniciou o seu trabalho em prol da expressão e criatividade dos doentes mentais do Centro Psiquiátrico Nacional de Pedro II. Aqui, iniciou a obra que foi e é merecedora da atenção de investigadores, médicos, psicólogos, artistas, educadores, terapeutas ocupacionais e cidadãos de todo o mundo. A psiquiatra faleceu no dia 30 de outubro de 1999, mas a obra perdura no Museu de Imagens do Inconsciente, que a preserva, divulga e expande.

Nise da Silveira, exemplo de compromisso ético e pioneira na humanização

9 Na mesma entrevista refere que "[...] deram um jeito e eu entrei para a faculdade com quinze como se tivesse dezesseis.” (Ibidem, p. 16).

10 A primeira data de janeiro de 1936, quando o Governo de Vargas intensificou a perseguição contra os comunistas, mas foi libertada no mesmo dia. 
do asilo e nas ideias de reforma psiquiátrica (MELO, 2007), recebeu condecoraçóes, títulos e prêmios em diferentes áreas do conhecimento - saúde, educaçâo, arte, literatura, entre outras. Entre eles, importa referir que foi indicada para o prêmio Nobel da Paz, em 1998. Apesar de não ter seguido o caminho desejado pelos pais como pianista, a sua vida e o seu trabalho têm uma forte vinculação à arte.

\title{
A valorização da expressão das emoções e dos conteúdos internos
}

\author{
Manuela Malpique e os espaços de expressão: \\ formação no e do imaginário
}

Todo o lugar é, potencialmente, um lugar para se fazerem aprendizagens: pode, pois, aprender-se em todo o sítio. (CARNEIRO; LEITE; MALPIQUE, 1983, p. 9).

Aí residia certamente a sua eficácia terapêutica e educativa: a capacidade de oferecer um continente envolvente, seguro, catalisador (maternal) onde fosse possível criar, descobrir algo, - a forma de expressão, ou seja, o conteúdo, poderia ser plástica, verbal ou onírica. (CELESTE MALPIQUE, 2007, p. 39).

Como refere Zamith-Cruz (2012), na sua história de vida, Manuela Malpique frisa mais os espaços do que as pessoas da sua vida. Para Alberto Carneiro ${ }^{11}$, a atenção aos espaços, evidente na sua escolha por arquitetura e nos estudos teóricos que apresentou para a obtenção de diplomas, "[...] moldou a sua sensibilidade e deu-lhe a consciência para as questóes dos espaços, paras as implicaçóes destes nas suas actividades pedagógicas e ou terapêuticas." (2007, p. 34).

Os espaços têm importância para a pedagogia: como professora, relatou-o aos arquitetos e, como investigadora, estendeu essa consciencializaçáo a outras áreas de conhecimento. Para ela, a qualidade das propostas, como dos espaços físico e relacional, interfere nos processos e produções do indivíduo, podendo ser libertadores ou inibidores da criatividade.

Quando comecei a ser professora, procurei aprender a

11 E para Malpique: "Dei-me conta, no entanto, que toda a minha ação pedagógica foi profundamente marcada pelo facto de ter passado, como estudante, por uma escola de formação de Arquitectos." (1983, p. 5). 
linguagem plástica da criança e do adolescente, aspecto que os programas do então "desenho" e "educação visual" não contemplavam. Fundei com uma colega do curso de Arquitectura um "atelier de expressão livre", atelier que, ao longo de quinze anos, foi o verdadeiro laboratório da minha aprendizagem nesse campo. (MALPIQUE, 2002, p. 57 , grifos nossos)..$^{12}$

Manuela Malpique procurou, como professora de desenho, observar como "[...] nasce, cresce, pára ou regressa a expressáo criadora na criança e no adolescente." (1970, p. 8). Inspirado em Arno Stern ${ }^{13}$, criou o Atelier 61 $1^{14}$, de expressão livre, onde se trabalhava em grupo, que se constituiu na relação entre quem ia pintar e quem criou as condiçóes para se desejar pintar (LEITE; MALPIQUE, 1984). Desenvolveu cursos diversificados para crianças, de acordo com a idade, em grupos de no máximo oito elementos, com uma sessão semanal de 1h30min. Em 1975, o atelier fechou por exigências de carácter profissional e necessidade de reflexão sobre a aprendizagem realizada nos 15 anos do seu funcionamento.

A expressão livre despertou nela o interesse de associar-se ao tratamento e apoio ao diagnóstico de crianças e adolescentes em crise (MALPIQUE, 2002).

Interiorizei a importância da aprendizagem que se faz numa equipa pluridisciplinar [médicos, psicólogos, enfermeiros, educadores, assistentes sociais]. Tive oportunidade de reflectir sobre a minha própria prática, em estudos feitos.

Consegui, após um trabalho profundo sobre mim própria, delimitar o território entre a Pedagogia e a Terapia, não as isolando, mas procurando entender os pontos onde elas se tocam. (MALPIQUE, 2002, p. 60).

12 Em 1960, com Fernanda Alcântara, e a partir de 1965 com Elvira Leite, dirigiu um atelier de expressão livre "à margem da escola" (LEITE; MALPIQUE, 1984, p. 57).

13 Educador que viriam a conhecer após o fecho do atelier, no âmbito de uma pesquisa sobre espaços da relação pedagógica. Esse encontro permitiu a Manuela Malpique fazer um balanço sobre aproximação ou não do seu atelier com a Académie du Jeudi, espaço de Arno Stern (ibidem).

14 De 1967 a 1975, manteve a orientação e as atividades, tendo sido acrescida a área da Expressão pela Palavra, orientada por Luísa Dacosta (ibidem). 
Decorrente do seu trabalho, alerta-nos que a interpretação das pinturas não pode descurar da situação da criança enquanto pinta, da intenção que figura, dos seus comentários e de que a evolução das pinturas de uma criança durante a psicoterapia é relevante quando encerra grande carga emocional.

\section{Da Secção de Terapêutica Ocupacional e Reabilitação à fundação do Museu de Imagens do Inconsciente}

Antes de Nise da Silveira se dedicar ao setor de Terapia Ocupacional do hospital, criado pelo médico Fábio Sodré, os doentes eram ocupados no serviço de limpeza e de lavandaria.

Para revitalizar aquele espaço, inaugura, em 1946, dezessete núcleos, entre os quais o de pintura, que foi aquele a que Nise da Silveira mais se dedicou, tanto pela possibilidade de pesquisa sobre a esquizofrenia como pela oportunidade de tratamento, que se começava a vislumbrar:

A pintura mostrava mais do que as outras atividades, porque trazia retratos do mundo interno do pintor, como se fosse possível ver através de frestas o que estava acontecendo dentro da cabeça do doente, coisa impossível com a palavra. [...] A pintura revelava, contudo, um mundo interno que eu ia juntando e estudava em séries, espalhando pelo chão os quadros. Ficava de joelhos olhando horas e horas, comparando, analisando, esquecida dos colegas que não aderiram à minha proposta. (SILVEIRA, 1987 apud MELLO, 2009, p. 93).

Nise da Silveira inspirou-se na psicologia analítica de Jung e articulou ideias do poeta Antonin Artaud e de autores como Merleau-Ponty, Bachelard, Klee, Arno Stern, Worringer, Dubuffet, Lain, Kaepelin, Bleuler, H. Simon, K. Schneider, Freud e Jung. Contou ainda com a colaboração de Almir Mavignier, artista brasileiro que, antes de colaborar com Nise, era funcionário burocrático do hospital e teve um papel central na instauração do atelier de pintura.

De acordo com Weinreb (2003), fá-lo quando se percebe que a atividade plástica facilita a comunicação não verbal dos doentes mentais por meio das imagens.

A observaçáo ensinou-nos que a atividade criadora dêsses doentes exprime não só as suas vivências angustiantes, delírios, alucinações, metamorfoses, transformaçōes do mundo, mas muitas vezes também seus esforços instintivos 
de defesa, sua luta comovedora para a reconquista da realidade. (SILVEIRA, 1970, p. 12).

Encontrou no jovem Almir Mavigner o interesse em colaborar na ampliação das oficinas para incluir a pintura e a modelagem. Esse artista e cofundador do atelier convidou outros artistas e críticos de arte (Mário Pedrosa e Ferreira Gullar) a conhecerem o trabalho do atelier e foi marcante para o desenvolvimento de exposiçóes, base para a criação do Museu de Imagens do Inconsciente.

Nise da Silveira procurava compreender o dinamismo psíquico da esquizofrenia e o tratamento por intermédio de terapêuticas da expressão permitia-lhe interpretar a história do paciente. Orientava Mavignier e os outros monitores-terapeutas a não interferirem nos trabalhos dos clientes do Engenho de Dentro. Segundo Mello (2001), as oficinas atraíram pessoas que se encontravam abandonadas nos pátios do hospital, incógnitos, vestidos com uniformes que denunciavam a sua condição, e que vão ser reconhecidos como seres excepcionais, com uma capacidade de expressão extraordinária, como Emygdio, Raphael, Adelina, Isaac, Carlos, Fernando, Abelardo, Octávio, Lúcio. E, para Pedrosa, "[...] os protagonistas, à medida que as coisas que faziam, pintura, escultura ou o que fosse, iam ficando conhecidas, iam sendo objeto de apreciação cada vez mais por si mesmos." (1980, p. 9).

De acordo com Nise da Silveira (1981), o atelier era um lugar agradável, amplo e com janelas abertas para a entrada do ar e para o vislumbre do exterior, para as árvores; era um lugar significativo para os clientes, testemunhado pela escolha do recinto do atelier como motivo para pintar. Escola viva, os ateliers de pintura e modelagem estavam imbuídos de um "ambiente de aceitação e simpatia e livre produção de formas, podia desabrochar-se sem a interferência de quem quer que fosse, médico ou monitor." (p. 37).

Em 23 de dezembro de 1946, foi inaugurada a primeira exposição dentro do próprio Centro Psiquiátrico Nacional, menos de três meses após o início das atividades do atelier de pintura. Devido à repercussão que teve nos meios de comunicação, realizou-se a Exposição de Pintura dos Alienados do Centro Psiquiátrico Nacional, no prédio do Ministério da Educação e Saúde, no Rio de Janeiro. No Museu de Arte Moderna de São Paulo, em 1949, posteriormente no Saláo Nobre da Câmara dos Vereadores, no Rio de Janeiro, realizou-se a mostra 9 Artistas do Engenho de Dentro. Em 1950, estiveram no I Congresso de Psiquiatria, em Paris, 98 obras do atelier.

$\mathrm{O}$ volume e qualidade das obras e, acima de tudo, o trabalho de Nise da Silveira e de Almir Mavignier, inspiram a criação do Museu de Imagens do Inconsciente. Fundado em 1952, coloca o Brasil como um dos países pioneiros na 
organização de coleçóes de obras de arte $_{b r u t a}{ }^{15}$, desprovidas do caráter acadêmico dos conceitos de arte, mas que náo deixam de surpreender pela sua qualidade estética e servir de mote para reflexóes e debates (JÚNIOR, 2016). No Museu de Imagens do Inconsciente, encontra-se toda a coleção de desenhos, pinturas e modelagens. Revelando a sua importância para o patrimônio cultural brasileiro, foram catalogadas 128 mil obras, das $350 \mathrm{mil}$ do seu acervo, pelo Instituto do Patrimônio Histórico e Artístico Nacional.

\section{A formação dos profissionais da emoção de lidar}

\section{Manuela Malpique e a formação em Imaginativa Onírica}

O Imaginário constitui a principal referência na intervenção psicopedagógica e psicoterapêutica de Manuela Malpique. Caracteriza-o como um aspecto central, dinâmico, de um Eu em situação, pertencente à lógica do irracional e conjunto do psiquismo individual e coletivo, afetivo e cognitivo e motor - lugar de saberes (MALPIQUE, 1998). Mais ainda, o imaginário é "[...] fundo e matriz de qualquer cultura, objecto antropológico por excelência, matéria prima e princípio de toda a criação intelectual [...]" (MALPIQUE, s.d.) ${ }^{16}$. Virel (1965) alerta para dois aspectos, aparentemente opostos, do imaginário: um visa apenas o indivíduo isolado e outro o indivíduo que vive e pensa no seio de uma comunidade humana. $\mathrm{O}$ pensée onirique ocorre em qualquer momento de aparente liberdade, dentro de nós, durante o sonho ou enquanto sonhamos acordados. No isolamento do mundo. Já o pensée mythique corresponde ao que construímos em contato com os outros homens, a partir de imagens comuns a todos os membros da comunidade. Para André Virel, os mitos são o fruto de um pensée onirique comum, daí considerar-se que os dois aspectos anteriormente referidos não se opóem, mas sim complementam-se.

A educação tende a enaltecer o universo intelectual em detrimento da relação ou dimensão afetiva, algo paradoxal para Manuela Malpique, dado que, ao trabalhar com as pessoas, o profissional da educação não pode anular o seu lado sensível. Manuela Malpique, em carta de 19 de outubro de 1996, dirigida a Nise da Silveira, revela que:

15 Definição do pintor francês Jean Dubuffet, 1945

16 Descrição presente na página 10 do seu Currículo Científico, quando explica o conteúdo do livro Mim mesmo o outro, in Metáforas e metamorfoses do corpo, não publicado, uma co-autoria com André Virel e Isabel Martins. 
A nossa Faculdade é, como na maioria das escolas, dominada pelo racional. Mas o saber racional, como sabemos, só se pode construir com a ajuda do imaginário. [...] Nem o racional nem o irracional têm realidade autónoma: um não é nada sem o outro.

A emoção é uma parte essencial na maquinaria da razão. A razão sem emoção será lógica, mas não racionalidade.

Malpique (1992) acreditava que o confronto dos profissionais da educação com o seu imaginário (pessoal e de grupo) concorre para a descoberta de um potencial criativo e é garantia de uma atitude de maior abertura, flexibilidade e criatividade na relação educativa. No âmbito da disciplina Desenvolvimento Socioemocional e Técnicas de Expressão e em cursos breves de Iniciação à Imaginativa Onírica ${ }^{17}$ convidava os estudantes "[...] à conquista do conhecimento, no diálogo com autores, mas simultaneamente à conquista de si mesmo, no diálogo entre o eu e a memória, o eu e o imaginário, o eu e a imagem de si, e a sua inscrição em projectos de futuro." (FELGUEIRAS, 2007, p. 13). Essas aulas/sessóes organizavam-se em torno de leitura e comentário de textos, individual ou em grupos de oito a dez elementos, em sessóes de descentraçáo ou sonho acordado com cada um dos grupos ou cada participante, momentos de encontro com fantasias, ativação de processos criativos, necessários ao bem-estar, equilíbrio e abertura na vida, pessoal e profissional.

Constituía-se num momento de aprendizagem vivencial no campo do imaginário, pelas histórias de vida e imaginativa onírica. Não ocorria uma relação educativa apenas em nível manifesto da comunicação verbal, mas também se desenvolvia em termos dos afetos, das fantasias - do inconsciente (MALPIQUE, 1983). Importa aqui salientar que afetos, de acordo com Damásio, “[...] é uma vasta tenda sob a qual [se] coloc[a] não só todos os sentimentos possíveis, mas também as situaçóes e os mecanismos responsáveis [...] pela produção de açóes cujas experiências se tornam sentimentos." (2017, p. 146). Sendo a vida acompanhada por sentimentos, enaltece a sua presença nos contextos educativo e terapêutico, por serem fundamentais para potenciar o processo intelectual e criador e a sua ausência comprometer a natureza humana (p.148).

O material onírico é um signo que remete para o inconsciente (PIERI, 2005), tornando acessíveis conteúdos inconscientes e aproximando-os da compreensão (JUNG, 2012). Nesse contexto, a arte reconstitui a unidade do ser humano: corpo/

17 Por exemplo, em 1989, Manuela Malpique orientou, na APPACDM de Viana do Castelo, um curso breve de Iniciação à Imaginativa Onírica 
espírito, inteligência/sensibilidade. Na formação em imaginativa onírica emergem as imagens (imagens de histórias de vida, oníricas e mitos de contos de fadas), um dos produtos dos domínios das Ciências da Educação, cujo campo é o imaginário e a função psíquica a imaginação (MALPIQUE, 1996). Define as imagens como vivências, reforça que elas podem ser primordiais ou ancestrais, viajam no espaço e no tempo e têm as suas defesas para se libertarem do pensamento. A imagem onírica é o diálogo entre o Eu e o Inconsciente (MALPIQUE, 1996):

De algum modo a pessoa fica surpreendida, não conhecia aquele seu lado, aquelas suas imagens, aquelas suas sensaçóes. E, portanto, isso é extremamente positivo, emerge muitas vezes uma força interior até aí desconhecida. Há uma aprendizagem muito interessante em imaginativa onírica. É que a vida é feita de aspetos positivos e negativos $[\ldots]$ e todos $[\ldots]$ vão contribuir para aquilo que somos hoje. (Entrevista a Isabel M.- n. ${ }^{\circ}$ ).

Nessas aulas, em que o espaço é percebido como quadro de vida, matéria de açóes do nosso quotidiano (MALPIQUE, 1995), acontecem processos profundos, desde que desejados pelas pessoas envolvidas, que suscitam o seu desenvolvimento e o seu crescimento afetivo (MALPIQUE, 1998).

Testemunho:

Quando tínhamos dores, quando tínhamos imagens, vivências imaginárias dramáticas, no fundo isso fazia-nos também refletir e questionar. Porquê esta imagem? Porquê esta situação? O que é que eu vivi que fez emergir no meu imaginário esta forma? Mesmo quando as imagens e situações são mais enigmáticas, mais dramáticas ou mais doces ou mais poéticas, de qualquer modo a pessoa está extremamente mexida, recetiva, está a conhecer algo de si que desconhecia e, portanto sente-se gratificada. Acolhe as imagens como uma dádiva. Empolgada! É porque nos empolga mesmo. É porque a pessoa conseguiu entrar no processo. (Entrevista a Isabel M.- ${ }^{\circ} 1$ ).

A imaginativa onírica é então uma técnica que permite a eclosão de um imaginário, de imagens que tecem um pensamento em rede, do domínio do irracional (MALPIQUE, 1996). Essa técnica, quando associada à psicoterapia, dissolve bloqueios neuróticos e permite, segundo Virel (1993), uma libertaçáo da criatividade, um renascimento, uma reintegração mais harmoniosa do ego. 
Numa prática de décentration não se pretende apenas relaxar o corpo para acalmar a psique, mas sim proporcionar a percepçáo espontânea de sensaçóes corporais involuntárias. Para Malpique (1998), ocorre uma iniciação para haver uma ruptura, a morte; a razão deixa de ser exclusiva e origina-se uma outra racionalidade, fundada pela razão sensível. É no confronto com o seu imaginário que o educador se pode abrir ao estudante e/ou formando, não lhe impondo, sistematicamente, a sua razão. E, segundo Malpique, essa técnica de raiz terapêutica é usada num processo que, sem deixar de ter as exigências éticas e deontológicas de uma terapia, tem uma vertente pedagógica.

Como relembra Felgueiras (2007), a sua ação educativa concretizava-se na atenção ao estar perante o outro, numa comunicação existencial profunda. Algo que nos leva a identificar a sua atuação com uma relação de ajuda ótima, para Rogers (1977), criada por uma pessoa psicologicamente madura, pois a sua capacidade de criar relaçóes que facilitem o crescimento do outro como uma pessoa independente mede-se pelo desenvolvimento que ela própria atingiu. Ao afirmar, "fui tomando consciência, ao longo do tempo, da minha finitude, e por isso tive necessidade de educar-me e transcender-me" (MALPIQUE, 2002, p. 131), vai ao encontro do que Damásio (2000) acredita ser a coisa mais indispensável do nosso quotidiano - o recordar a nós próprios e aos outros a fragilidade, finitude e singularidade como seres humanos.

Manuela Malpique partilhava com os estudantes e formandos a sua crença de que o conhecimento é ilimitado e assume a forma de uma interrogaçáo contínua e com interpretaçóes múltiplas. E é na possibilidade de concretizar passeios imaginários que a pessoa se volta para a sua experiência de vida ou para o conhecimento que tem de outras histórias (MALPIQUE; JARDIM, 1998). O demorar nesse passeio permite muitas vezes ao indivíduo aperceber-se do cripto das mensagens, de símbolos "[...] que o fazem pensar e re-interpretar e reconstruir e re-conhecer uma outra ideia [...]” (1998, s/p). Para Manuela, isso é uma atitude hermenêutica, no sentido ricoeuriano, que se plasma no buscar as raízes e os desejos do ser, dialogar com o Outro que coabita comigo (1998).

\section{A Experiência de Nise da Silveira na Casa das Palmeiras}

Em 23 de dezembro de 1956, Nise da Silveira, na presença de alguns psiquiatras e de vários amigos, inaugura a Casa das Palmeiras ${ }^{18}$, o primeiro serviço a atuar como ponte entre o hospital psiquiátrico e a reintegração na sociedade, 
um projeto de desinstitucionalização de pessoas internadas em hospitais psiquiátricos no Brasil. Trata-se de um local que previne a discriminação por parte dos profissionais da saúde, evitando os rótulos e onde os diagnósticos não são centrais para atender às especificidades de cada indivíduo, pois mascaram a sua real identidade. Nise não percebia os problemas psíquicos como perturbaçóes que conduzem à doença mental e física, a serem tratadas sem considerar a pessoa no seu todo. Perante o número elevado de reinternaçóes, Nise pensou na utilidade de um setor do hospital ou de uma instituição que funcionasse como ponte entre o hospital e a sociedade (SILVEIRA, 1986). A artista plástica Belah Paes Leme e a assistente social Lígia Loureiro auxiliaram na concretização do projeto dessa instituição, que viria a ser reconhecida como de utilidade pública pela Lei n. ${ }^{\circ}$ 376, de 16 de outubro de 1963. Embora inicialmente pensada para indivíduos outrora internados, também acolhe pessoas com perturbaçóes psiquiátricas e que não chegaram a ser internados.

O principal método de tratamento utilizado na Casa das Palmeiras é a terapia ocupacional com o intuito de "coordenar intimamente olho e mão, sentimento e pensamento, corpo e psique, primeiro para a realização do todo específico que deverá vir a ser a personalidade de cada indivíduo sadio." (SILVEIRA, 1986, p. 11). É concretizado por meio de atividades expressivas, ligadas às artes plásticas, que envolvem a função criadora, que existe de formas mais ou menos desenvolvidas em todos os indivíduos.

Nise (1981, 1986), ao longo das suas obras, foi revelando a sua preferência pelo termo emoção de lidar em vez do termo terapia ocupacional, adotado por ingleses e americanos. Inspira-se na utilização dessas palavras por um cliente da Casa das Palmeiras (SILVEIRA, 1986), Luiz Carlos, quando manipulava lá para a criaçáo de um gato que no Natal ofereceu ao menino Jesus, e revela o efeito da atividade criativa:

Gato, simplesmente angorá do mato,

Azul olhos nariz cinza

Gato marrom

Orelha castanho macho

Agora rapidez

Emoçáo de lidar. (SILVEIRA, 1986, p. 19).

Distinguiu, também, o seu método da arte-terapia. Considerava a designação inadequada pela conotação de valor e qualidade estética contida na palavra arte. Nunca pretendeu que os seus clientes da Casa das Palmeiras, ou qualquer outro contexto de atuação, realizassem obras de alta qualidade artística, embora reconheça que por vezes acontece (SILVEIRA, 1986). Segundo Júnior (2009) 
revela, ao invés, preferiria os termos linguagem plástica ou expressão plástica. Para Silveira, terapeuticamente, o que importa é permitir a livre expressão do indivíduo para que o seu mundo interno dissociado se reconstitua e assim reintegre o mundo externo. Interessa-lhe, pois, o processo criador, a expressão de símbolos eternos que se encontram no inconsciente. Os símbolos constituem-se sempre como um desafio à reflexão e compreensão, daí advém a sensibilidade que provoca e a impossibilidade de apreciaçấo estética (JUNG, 2012). Nos ateliers por si coordenados, as atividades são de livre expressão, condição necessária para a expressão espontânea das emoções, vivências e afetos, muitos não verbalizáveis.

Segundo Silveira, "[...] os conhecimentos técnicos não constituem tudo em qualquer profissão. A pessoa humana de cada um, a sensibilidade, a intuição, são qualidades preciosas." (1981, p. 67). O terapeuta deixa em aberto o caminho da cura individual, náo invalidando a reciprocidade do encontro entre si e o cliente, ambos implicados numa interação, que se valoriza ainda mais quando prima pelo diálogo. No entanto, convictos que circunscrevendo a atuação do monitor à sua habilidade num determinado ofício faria com que ele se interessasse mais pelos trabalhos realizados do que pelos doentes (SILVEIRA, 1966), assumiu-se o relevo da formação. Organizou, em 1948, o primeiro Curso Elementar da Terapêutica Ocupacional. Era composto pelas seguintes matérias: Noçóes de Psicologia Normal e de Psicopatologia, Noçóes de Teoria da Terapêutica Ocupacional, e uma parte prática. Essa era realizada nos núcleos de atividades existentes no Centro Psiquiátrico Nacional e no âmbito de cursos e estágios em diversas instituiçóes - na Sociedade Pestalozzi, no Instituto de Surdos e Mudos, no Serviço Nacional de Aprendizagem Industrial, na Escolinha de Arte do Brasil, no Instituto Brasil-Estados Unidos, etc. A intenção era promover cursos que dessem resposta às necessidades que emergiam, e Nise (1966) afirma que corresponderam às expectativas.

$\mathrm{O}$ atelier de pintura livre foi um dos primeiros a funcionar na Casa das Palmeiras. Limitado no espaço físico por quatro paredes, mas ilimitado no espaço psicológico. Nele encontram-se as condiçóes materiais - papel, lápis, pincéis, tinta, água, mesa, cadeiras, estante, janelas - e as ambientais - afeto, livre expressão e movimentação pelo espaço, descontração - para o cliente dar relevo às suas emoçóes, expressando-se por meio de formas simbólicas, por vezes de forma infantil e tosca (SILVEIRA, 1986).

Para Nise:

A pintura livre é uma das mais importantes atividades da Casa, configurando imagens inconscientes reveladoras da problemática do indivíduo e que, mesmo não sendo interpretados intelectualmente, podem ser apreendidas 
por via de percepçóes inconscientes, influindo assim sobre a ampliaçáo do desenvolvimento de seus autores e tendo mesmo açáo terapêutica. (SILVEIRA, 1986, p. 22).

O conhecimento do indivíduo é concretizado pelos aspetos percetíveis por intermédio de uma observação cuidada e atenta (pela relaçáo que estabelece com o monitor e os seus colegas, a forma como entra no atelier, como se senta) e pelos trabalhos (se o assina ou náo, por meio das cores que escolhe, dos temas presentes, entre outros).

Ao monitor-terapeuta pede-se que tome posiçóes fora de dogmas preestabelecidos, distanciando-se da visão médica que apenas vê nas criações da imaginação coisas patológicas e identifica as ideias, imaginações e açôes como material que advém da doença, para, assim, vislumbrar a estrutura da psique (SILVEIRA, 1986). Como refere Jung, "Usando-se bom gosto e parcimônia, pode resultar uma interessante visão geral de como a criação artística está entrelaçada com a vida pessoal do artista, por um lado, e, por outro, como ela se projeta para fora desse entrelaçamento." (2012, p. 68).

Jung introduziu uma nova compreensão do ser humano, que transpóe os limites da psiquiatria e da psicologia. A identificação de Nise da Silveira com o trabalho de Jung deve-se, pensamos nós, ao fato dele se preocupar mais com o desenvolvimento mental do indivíduo como um todo. Procurava os meios terapêuticos eficazes para ajudar as pessoas a lidar com suas necessidades atuais, não apenas o tratamento ou a cura de distúrbios psíquicos. Jung considerava que as fantasias esquizofrenicas não tinham menos valor do que os sonhos; para ele, ambos são fenômenos naturais que não iludem, não mentem, mas comunicam ingenuamente o que são e o que pensam (JUNG, 1995). Convidava a pintar as imagens dos seus sonhos e outras fantasias, trazia-os à realidade concreta (REIS, 1997).

Nise, conhecedora da obra de Jung, iniciou a correspondência com o psiquiatra depois de uma descoberta inquietante. Entre as imagens caracterizadas pela desagregação (corpos desmembrados, árvores cortadas, etc.) produzidas pelos clientes esquizofrênicos, apareciam símbolos de ordem, circulares, não expectáveis pela própria condição da doença. Fotografou mais de 100 imagens dessas e enviou-as com uma carta a Jung, em que questionava se estas corresponderiam a mandalas ${ }^{19}$. Recebeu rápida resposta de Jung, confirmando que correspondiam ao

19 Círculo mágico que se encontra em todas as civilizações, símbolo do centro, da meta e do si-mesmo, que aparece com mais frequência em situações de perturbação e indecisão (JUNG, 1995). 
poder autocurativo da mente, e pedindo mais informaçóes sobre os casos clínicos dos autores das imagens. Iniciaram-se dois anos de correspondência, que originou a exposição de mandalas no II Congresso de Psiquiatria, em Zurique, em 1957.

Para Nise, o inconsciente é um conjunto de representaçóes, pensamentos e recordaçóes ligadas ao $\mathrm{Eu}$, na qualidade de já/ou ainda não serem conhecidas pelo $\mathrm{Eu}$ - inconsciente pessoal - e por um patrimônio psíquico de nós como seres coletivos- inconsciente coletivo formado pelos instintos e por conteúdos que foram herdados da evolução da humanidade, que renasce em cada estrutura individual, os arquétipos ${ }^{20}$.

Para Jung, a imagem é entendida como forma expressiva fundamental, como elemento que antecede, motiva e orienta o pensamento e a razão, tem poder e valor em si própria; invalida a falsa crença que a função intelectual tem primazia sobre a emotiva e afetiva. Jung sugere que a psique é constituída por dois tipos psicológicos e que cada um se desenvolve segundo quatro funçôes psicológicas, funções de orientação da consciência no mundo exterior, que podem ser introvertidas ou extrovertidas (SILVEIRA, 1966). Daí supor uma constante e inevitável relação entre as atividades de percepção - sensação e intuição - e as funçóes de abstração - sentimento e pensamento. Segundo o nosso tipo psicológico, uma dessas funçóes será a função principal, a mais exercitada, aquela com a qual nos orientamos e adaptamos à realidade. É também denominada função superior, a qual pertence na totalidade à nossa consciência (JaCOBI, 1947). E Nise (1966) relembra que se desprezarmos a função inferior, presente absolutamente no inconsciente, essa desvincula-se da consciência e torna-se autônoma. Por exemplo, se a função inferior é o sentimento, recorre-se a atividades que conduzam à expressão de emoçóes artes plásticas, música e teatro - e que impliquem relaçóes interpessoais, dado que a finalidade é a totalidade das quatro funções à disposição do indivíduo.

A atenção que Nise revela pressupóe a intenção de pelo menos se aproximar desse ideal. Como revela Jacobi (1947), a função inferior manifesta-se pelo seu carácter difuso e atua de forma autônoma, desde o inconsciente, quando lhe convém. Os quatro tipos de funçóes e a que se destaca têm habitualmente apenas validade teórica, pois é raro essas manifestarem-se na sua pureza; aparecem sim em tipos mistos, tornando-se complexo determinar o predomínio de uma função.

20 Para Jung (1995), o conceito arquétipo deriva da observaçấo de que os mitos e os contos da literatura universal encerram temas bem definidos, que reaparecem mediante fantasias, sonhos, nas ideias delirantes e ilusôes dos indivíduos. Quanto mais nítidas forem essas imagens, mais imbuídas estáo em vivências afetivas. 
Jung, tendo sido o primeiro europeu a usar a arte como terapia, exaltava a importância da expressão para o crescimento espiritual e considerava que as coisas do mundo de fora e de dentro de nós adquirem uma existência mais plena quanto mais somos capazes de imaginar (PIERI, 2005).

O governo brasileiro funda, por meio de Jairo Goldberg, só em 1987, o Centro de Atenção Psicossocial (CAPS) Luiz Cerqueira, em São Paulo. São regulamentados os CAPS pela portaria de 20 de março de 2002, n. ${ }^{\circ} 189$. Eles representam um serviço de saúde mental para pessoas que necessitam de reinserção social, oferecendo acesso a recursos terapêuticos, que vão além de consultas e prescrição de medicamentos, como acesso à educação ou fortalecimento de laços familiares e comunitários, entre outros. Inspirados no trabalho de Nise da Silveira, de abordagem junguiana, diferenciam-se pela abordagem psicanalítica aliada a um discurso social.

\section{Conclusão}

Apresentamos duas autoras cujos trabalhos são relevantes para pensar a educaçẫo e a terapia. Nas suas áreas de atuação e paixão dão espaço ao $\mathrm{Ser}$, evidenciando que a aprendizagem mais essencial é quem nós somos. Educar é permitir que o outro se afirme como pessoa por meio das experiências pessoais e sociais, de acordo com as suas necessidades.

As suas reflexóes e práticas eram sustentadas em diversas áreas, como diversos foram os contextos das suas atividades profissionais. Diversidade que em vez de ser percebida pelos seus colegas de trabalho como enriquecedora, respectivamente, para o campo educativo e para o campo terapêutico, para os estudantes e para os clientes, era fonte de incompreensão das suas obras.

Ambas conciliaram aspectos artísticos e científicos. Por exemplo, Nise organizava as manifestaçóes artísticas dos clientes por temas ou por ordem cronológica, com o intuito de estabelecer ligaçóes e compreender o seu estado emocional. As obras constituíam material de estudo sobre a esquizofrenia e eram um meio terapêutico para a recuperação em termos mental e social. Segundo Damásio (2017), as pinturas, tendo uma função homeostática, já serviram - e reforçamos que ainda servem - para reflexão, ajudar a clarificar a realidade e a organizar conhecimentos. O trabalho de Nise é um exemplo do diálogo entre a arte, a psiquiatria e a educação, que pôs em evidência que o homem é uma constante fonte de informação e comunicação, mesmo não verbal, e quão forte é o impulso criativo que emerge do inconsciente. Do mesmo modo que Jung (2012), defendiam a limitação da criação artística ao processo psíquico e não 
destacavam as consideraçóes sobre obras de arte, nem se preocupavam com a essência da arte em si.

Os trabalhos dessas autoras revelam que o recurso às atividades expressivas está presente em contextos educativos e em contextos clínicos. Ambas valorizaram os afetos, o relacionamento, o espaço (interno e externo) e as vivências neles concretizadas. Compete ao educador ou facilitador construir um ambiente de aprendizagem eficaz, ter uma atitude de respeito pela diferença, capacidade imaginativa, organizar o trabalho pedagógico e de investigação, pensar estratégias que permitam a participação de todos. Também auxiliar as crianças, os jovens e os clientes a tornarem-se mais criativos e competentes na comunicação interpessoal. Nise da Silveira e Manuela Malpique, por meio da emoção de lidar, utilizavam as atividades expressivas, preferencialmente a pintura, com fins terapêuticos e de aprendizagem. Pretendiam aceder ao interior do indivíduo, compreendendo as suas relaçôes com o meio e proporcionando a expressão de emoçóes. A expressão é assim percebida como via de diluir as fronteiras entre o consciente/inconsciente e interior/exterior.

As temáticas e autores que inspiraram as suas obras estâo longe de esgotar as possibilidades de estudo e não se confinam aos campos da educaçáo e da saúde mental, mas são de relevo para todos/as nós, nomeadamente em termos da consciência e das suas componentes - subjetividade, integração de experiências (DAMÁSIO, 2017) - e do desenvolvimento pessoal. A nossa sociedade, embora informada sobre os fazeres e saberes da arte em contextos educativos, continua a dar pouco espaço para atividades de expressáo livre, por meio das artes. Essa situação convoca o educador à organização pedagógica de projetos que envolvam crianças e jovens em espaços e tempos de expressão livre, na demonstração da sua importância para o desenvolvimento holístico da pessoa.

\section{Referências}

BEZERRA, Elvira. A Trinca do Curvelo. Rio de Janeiro: Editora Topbooks, 1995. Bibliografia consultada na biblioteca de Nise da Silveira/Museu de Imagens do Inconsciente.

CALIXTO, Carolina Fernandes. Nise da Silveira e a "república do curvelo": intelectuais comunistas do cone sul sob a mira do TSN. Acervo, Rio de Janeiro, v. 30, n. 2, p. 206-223, jul./dez. 2017.

CARNEIRO. Alberto. Manuela Malpique - Alguns Espaços da sua realização. In: Reinventar a Educaçáo, Reinventar a Utopia Democrática: Manuela Malpique. Porto: Universidade do Porto, 2007. p. 33-37. 
DAMÁSIO, António. A estranha ordem das coisas: a vida, os sentimentos e as culturas humanas. 1. ed. Lisboa: Círculo de Leitores, 2017.

DAMÁSIO, António. O Erro de Descartes: emoção, razão e cérebro humano. Tradução de Dora Vicente e Georgina Segurado. Mem Martins: Publicaçóes Europa-América, 2000.

FELGUEIRAS, Margarida Louro. Manuela Malpique. A Mulher, a Investigadora e a Pedagoga (1932-1999). In: Reinventar a Educaçáo, Reinventar a Utopia Democrática: Manuela Malpique. Universidade do Porto, Porto, 2007. p.7-32.

GOMES JÚNIOR, Eurípedes. Conhecendo o mundo interior: Museu, Arte e Loucura. Revista Museologia \& Interdisciplinaridade, v. 5, n. 10, p. 168-184, jul./dez. 2016.

GOMES JÚNIOR, Eurípedes. O Museu de Imagens do Inconsciente: das coleçôes da loucura aos desafios contemporâneos. Dissertação (Mestrado em Museologia e Patrimônio) - UNIRIO, Rio de Janeiro, 2009.

GUARINELLO, Norberto L. Memória coletiva e história científica. Conferência proferida por ocasião do CONGRESSO DE CIÊNCIAS HUMANAS DAS UNIVERSIDADES FEDERAIS DE MINAS GERAIS E S. JOÃO DEL REI, 1., 1993. Anais... São João Del Rei, maio 1993.

JACOBI, Jolande. La Psicologia de C. G. Jung. Madrid: Espasa Calpe, 1947, p. 31-79. FPCEUP. ESPÓLIO DA PROFESSORA DOUTORA MANUELA MALPIQUE. MM-DIF-DIV 0.10.6 (sub-série).

JUNG, Carl G. Memórias, Sonhos, Reflexóes. Rio de Janeiro: Nova Fronteira, 1995.

JUNG, Carl G. O espírito na arte e na ciência. Petrópolis: Vozes, 2012.

LEITE, Elvira; MALPIQUE, Manuela. Para uma troca de saberes: desenhar, pintar a dedo, modelar, pintar no Jardim-de-Infância. Lisboa: Ministério da Educação, 1984. Bibliografia consultada na biblioteca de Nise da Silveira/Museu de Imagens do Inconsciente.

MALPIQUE, Celeste. Pelo sonho é que vamos! In: Reinventar a Educaçáo, Reinventar a Utopia Democrática: Manuela Malpique. Porto: Universidade do Porto, 2007. p. 39-41.

MALPIQUE, Celeste; MALPIQUE, Manuela. Pintura a dedo: Seu interesse terapêutico e reeducativo em crianças psicóticas ou com deficiências intelectuais. Revista Portuguesa de Deficiência Mental, v. 1, p. 127-138, jan. 1970. 
MALPIQUE, Manuela. A Vida e as suas histórias: Projecto, Vida e Posiçóes Existenciais. In: A Escola Primária: entre a imagem e a memória. Porto: Projecto Museu Vivo da Escola Primária, 2000, p. 65-72.

MALPIQUE, Manuela. Da Regressão: Fundamentos Psicopedagógicos para a definição da educação artística na adolescência. Boletim da Direçáo de Serviços do C.P.E.S., n. 5, p. 6-25, 1970.

MALPIQUE, Manuela. Histórias de Vida. Porto: Campo de Letras, 2002.

MALPIQUE, Manuela. Imaginativa: para a eclosão de um imaginário, a propósito de um espaço esquecido na formação dos educadores. Cadernos de Educaçáo de Infância, n. 23, p. 38-39, jul./ago./set. 1992.

MALPIQUE, Manuela. Na escola, o imaginário (dos alunos) é colonizado pela razão (dos professores)? In: Repensar a Escola. JORNADAS PEDAGÓGICAS, 1., 1996. Anais... Leiria: Universidade Católica Portuguesa, 1996, p. 7-17.

MALPIQUE, Manuela. Os Professores falam aos Arquitectos: aspectos metodológicos da apreensão do Espaço. A Urbanidade: Um conceito Pluridisciplinar a veicular, também, pela Escola. Porto: ESBAP. [Concurso para Obtenção do Diploma de Arquitecto], 1983.

MALPIQUE, Manuela. Pequenas Histórias: a Geografia das Crianças: Práticas e representaçôes de lugares do dia-a-dia de crianças portuguesas em idade escolar. Tese (Doutorado) - FPCEUP, Porto, 1995. v. I e II.

MALPIQUE, Manuela. Relatório da Disciplina: Desenvolvimento Socioemocional e Técnicas de Expressão. Porto: FPCEUP, 1998.

MALPIQUE, Manuela; JARDIM, Maria A. Cibercultura: uma Cibernética, uma Ciberinterpretação, uma Ciberescolha. In: CICLO DE ESTUDOS SOBRE O IMAGINÁRIO IMAGINÁRIO E CIBERCULTURA, 10., Recife, 1998. Anais... Recife, 1998. Disponível em: <http://www.yle-seti-imaginario.org/ downloads/anais-x-ciclo-A.pdf>. Acesso em: 09 set. 2014.

MELLO, Luiz Carlos (Org.). Encontros: Nise da Silveira. Rio de Janeiro: Beco do Azougue Editorial, 2009.

MELLO, Luiz Carlos. Nise da Silveira: a paixão pelo inconsciente. Quaternio Homenagem Nise da Silveira. Revista do Grupo de Estudos C. G. Jung, n. 8, 2001. Bibliografia consultada na biblioteca de Nise da Silveira/Museu de Imagens do Inconsciente. 
MELO, Walter. Maceió é uma cidade mítica: $\mathrm{O}$ mito da origem em Nise da Silveira. Psicologia USP, v. 18, n. 1, p. 101-124, 2007.

MELO, Walter. Nadando contra a corrente: a piracema-cultural de Nise da Silveira. In: VII ENCONTRO CLIO-PSYCHÉ: PSICOLOGIA, HISTÓRIA, ALTERIDADE, 7., 2006, Rio de Janeiro. Anais... Rio de Janeiro, UERJ, 4, 5 e 6 de outubro de 2006. p. 26-27.

PIERI, Paolo F. Introduçáo a Carl Gustav Jung. Lisboa: Ediçóes 70, 2005.

POMPEU E SILVA, José O.; REILY, Lucia (Org.). Marcas e Memórias: Almir Mavignier e o Ateliê de Pintura de Engenho de Dentro. São Paulo: Komedi, 2012.

REIS, Maria Luísa da Silva P. Transcrição do texto: A sabedoria do Sonho: Carl Gustav Jung. Documentário transmitido no programa Artes e Letras. Porto: Faculdade de Psicologia e de Ciências da Educação, 1997. Pasta MM-DIFCOR 09 (série).

ROGERS, Carl. Tornar-se Pessoa. Lisboa: Moraes Editores, 1977.

SANTOS, Esmeralda, LIMA, Isabel; JARDIM, Antónia M. Núcleo Interactivo Híbridos e Imaginários - NIHI - Mil e um sonhos e projectos que nos habitam. In: Reinventar a Educaçáo, Reinventar a Utopia Democrática: Manuela Malpique. Galeria do Palácio. Porto, Universidade do Porto, 2007. p. 47-48.

SILVEIRA, Nise (Coord.). Casa das Palmeiras: A emoção de lidar. Uma experiência em Psiquiatria. Rio de Janeiro: Editora Alhambra, 1986. Bibliografia consultada na biblioteca de Nise da Silveira/Museu de Imagens do Inconsciente.

SILVEIRA, Nise. Herbert Read: em memória. Quaternio. Revista do Grupo de Estudos C. G. Jung, Rio de Janeiro, n. 2. p. 5-16, 1970. Bibliografia consultada na biblioteca de Nise da Silveira/Museu de Imagens do Inconsciente.

SILVEIRA, Nise. Imagens do Inconsciente. Rio de Janeiro: Editorial Alhambra, 1981. Bibliografia consultada na biblioteca de Nise da Silveira/Museu de Imagens do Inconsciente.

SILVEIRA, Nise. Terapêutica Ocupacional: Teoria e Prática. Rio de Janeiro: Casa das Palmeiras, 1966. Bibliografia consultada na biblioteca de Nise da Silveira/Museu de Imagens do Inconsciente.

VIREL, André. Histoire de notre image. Genéve: Éditions du Mont-Blanc, 1965. Bibliografia consultada na biblioteca de Nise da Silveira/Museu de Imagens do Inconsciente. 
VIREL, André. Vivre sa Mort. Paris: L'Arbre Vert, 1993. Pasta MM-DIFBIBL 08.2 (sub-série). FPCEUP. ESPÓLIO DA PROFESSORA DOUTORA MANUELA MALPIQUE. MM-DIF-DIV 0.10.6 (sub-série).

WEINREB, Mara Evanisa. Imagem e desrazáo: Estudo da produção plástica de Manoel Luiz da Rosa (1961-2002). Dissertação (Mestrado em Artes Visuais), Instituto das Artes da Universidade Federal do Rio Grande do Sul. Porto Alegre, 2003.

ZAMITH-CRUZ, Judite. Histórias cruzadas de docentes: seis exploradoras de excepção. In: Cruz, Angélica C., MAGALHÁES, Maria J.; NUNES, Rosa S. Pelo Fio se vai à Meada: percursos de investigação através de histórias de vida. Lisboa: Ela Por Ela, 2012, p. 215-241. 